\title{
EXPRESS ASSESSMENT OF ROCKBURST HAZARD IN "NIKOLAEVSK" AND "INTERNATIONAL" MINES BY GEOACOUSTIC METHOD
}

\author{
Andrey Tereshkin ${ }^{1 *}$, Pavel Anikin ${ }^{1}$ and Dmitriy Migunov ${ }^{1}$ \\ ${ }^{1}$ Mining Institute of Far Easten Branch of Russian Academy of Sciences, Khabarovsk, Russia
}

\begin{abstract}
Measurements of parameters of acoustic emission were carried out on a number of burst hazard mineral deposits of the Far East and Transbaikalia. New data on features of phenomena of hazard forms of rock pressure on various sites of the mine are obtained. The technique of carrying out of measurements by "Prognoz L" local monitoring device is developed. Criteria of burst-hazard properties of the rock massif on a number of the mineral deposits, being developed by underground mining, were substantiated.
\end{abstract}

\section{Introduction}

Reliable and operational information about a geomechanical condition of the rock massif has an important meaning for the forecast and prevention of hazard phenomena of rock pressure. This information can be received by geophysical methods and measuring tools [1]. Micro seismic (seismoacoustic) and geoacoustic methods are most widely applied. It is possible to carry out both local and regional monitoring of rock massif condition by means of geoacoustic. Scale of monitoring (local or regional) depends on the used technical means. It is based on the experimentally observable and theoretically studied phenomenon of an acoustic emission (AE) which accompanies the process of a mechanical loading and destruction of rocks [2].

\section{Design and operating principle of the device}

Intensive development of microprocessor and digital technologies has created conditions for development of considerably more perfect geoacoustic portable device ("Prognoz-L") for local monitoring of bust-hazard in Mining Institute FEB RAS in recent years [5]. "Prognoz-L" allows to record a large number of the AE parameters, process and analyze the obtained information. It

\footnotetext{
Corresponding author: andrey.tereshkin@bk.ru
} 
considerably increases reliability of operational assessment of a geomechanical condition of the rock massif.

The portable device for local monitoring of burst hard "Prognoz L" consists of two main parts (fig. 1a): primary receiving converter (sensor) and measurement unit. Accelerometer AP99-1000 series (GlobalTest, Sarov) (fig. 1b) was chosen as primary receiving converter for the Prognoz L device by results of the detailed analysis, laboratory and field test.

Observed data and stories of operation of the device is stored on micro-SD flash card. The interface of exchange with cards of this format is realized by STM32F405 microcontroller in the form of the hardware module which allows to read out and record data without using a computing core of the microcontroller.
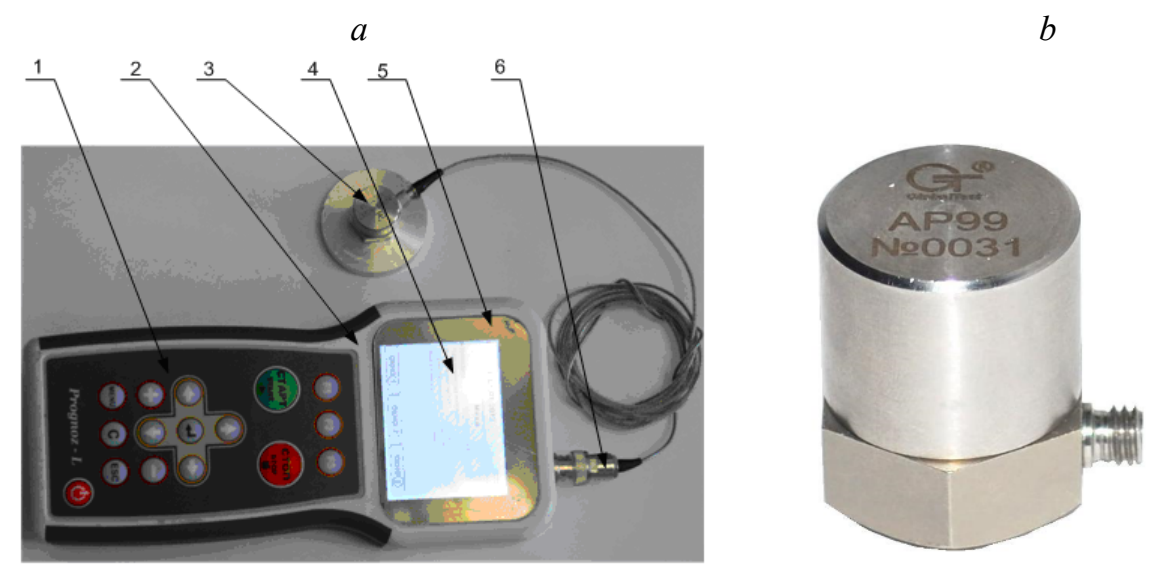

Fig. 1. Prognoz L device: a - measurement unit; b - AP99-1000 accelerometer 1 - keyboard; 2 - device housing; 3 - portable sensor (accelerometer); 4 - liquid-crystal display; 5 - polycarbonate protective glass; 6 - socket connection of the portable sensor

There are four modes of the device. Fist is measurement mode. Second mode is monitoring one; the user and engineering menu are used for the setting of the Prognoz L device.

Setting of the device is performed before the measurement of the AE parameters. Adjusted parameters are date, time, record to digital storage device, volume of sound. There is a possibility of adjustment of frequencies, amplitude and time filter of detection of $\mathrm{AE}$ of impulses. User and engineering menu are used for this purpose.

A number of algorithms for selection of the useful AE signals and filtration of technological interference of various nature is realized in the device of local monitoring.

For assessment of a condition of the massif the device of local monitoring "Prognoz-L" uses the following criteria: intensity of AE without visible influence of technological processes $\boldsymbol{N}_{A E}$ and an indicator $\boldsymbol{b}$ (amplitude distribution) [7]. The $\boldsymbol{N}_{A E}$ index of intensity allows to assess the achievement of the ultimate loads in the edge of regional part of rock massif. 
The index $\boldsymbol{b}$ characterizes the instability of process of deformation, increase of quantity of high energy impulses and is calculated by a formula:

$$
b=\lg \frac{N_{A \ni}^{1}}{N_{A \ni}^{2}} / \lg \frac{A_{2}}{A_{1}},
$$

where $\mathrm{b}-\mathrm{a}$ ratio of number of acoustic impulses with a different amplitude (energy); $A_{1}$ and $A_{2}$ - thresholds (levels of sensitivity of the device); $\mathrm{N}_{\mathrm{AE}}^{1}$ and $\mathrm{N}^{2}{ }_{\mathrm{AE}}$ - intensity of $\mathrm{AE}$ at various thresholds.

Optional AE parameters (spectral characteristics of $\mathrm{AE}$ of signals) are used besides the specified criteria $\left(N_{A E}\right.$ and $b$ ) for the assessment of a condition of the massif.

A number of original algorithms for the selection of the useful signals of AE and filtration of technological interferences of various nature is realized in the device of local monitoring. That is extremely important as measurements are very often taken in the composite noise situation of the underground mine.

\section{Research burst-hazard}

Field tests of the Prognoz L device were carried out in Nikolaevsk, Youzhnyi and Silinsk (JSC Dalpolimetall MMC), Glubokoe (PJSC "PPGHO") and the International mine (Alrosa) underground mines.

Assessment of a geoacoustic condition of the rock massif were carried out by the device of local monitoring in potentially burst-hazard mine caving. Here were obvious visual indications of positive pressure, such as; rupture of timbering, intensive rock cleavage of roof or boards of mine caving, mineral shooting on sites of the massif where the increased level of tension is observed by stationary seismoacoustic control systems [4].

The staff of JSC ALROSA made measurements by the Prognoz L device in April 5, 2018 (mark-779/-862). Most stressed sites of the rocks massif of the mine "International" were measured. The geology of mine course is presented by interlayer of dense, clay and lime dolomite. Rock are unstable, inclined to split. Local showings of oil are noted. Mine course is characterized as I class of gas hazard and as the II group on zones of showings of oil. Mine roof was partly split off during measurements No. 2,3,9.

Twelve measurements were made according to the figure 2 (7 points). Each of them took 510 minutes. Results of measurements are given in table 1 .

Local sites with high burst hazard degree are defined by results of measurements. Points No. $1,3,4$ are included. The category "HAZARD" is appropriated to this site.

Mean values of the measured AE parameters in Avtouklon's face mine "International" (mark -779/-862) are:

- Frequency of impulses is- $15113 \mathrm{~Hz}$;

- Duration of impulses - 34,5 ms;

- Amplitude of impulses - 32,5 dB 


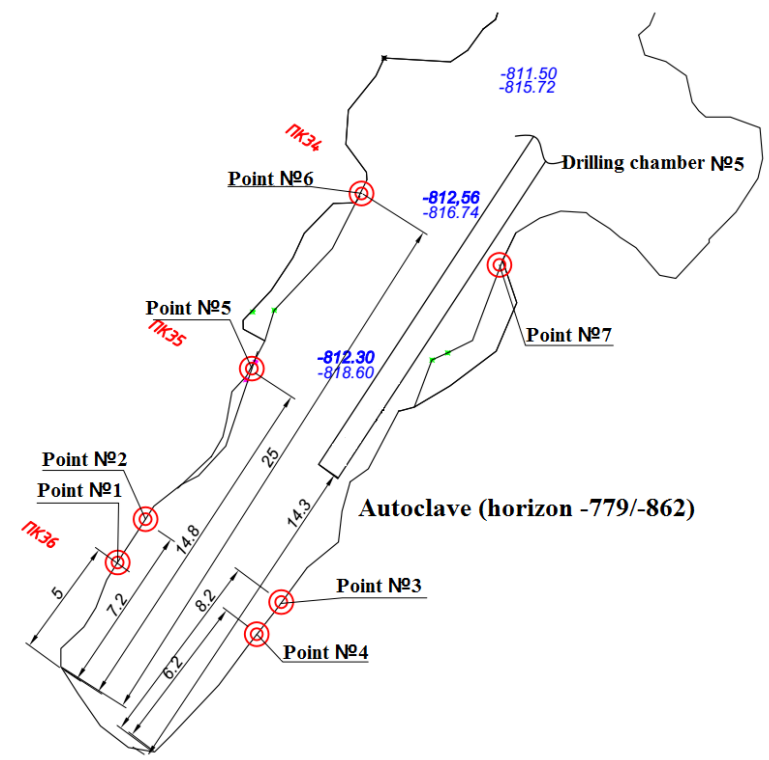

Fig. 2. The scheme of measurement points by the local device on the mine "International"

Table 1. Results of measurement of AE on the mine "International", 5.04.2018.

\begin{tabular}{|c|c|c|c|c|c|c|c|c|c|}
\hline \multirow[t]{2}{*}{ № } & \multirow[t]{2}{*}{ Time } & \multirow[t]{2}{*}{ Place } & \multirow[t]{2}{*}{$\mathbf{t}, \mathrm{min}$} & \multicolumn{2}{|c|}{$\begin{array}{l}\text { Threshold, } \\
\text { dB }\end{array}$} & \multicolumn{2}{|c|}{$\begin{array}{l}\text { Number of } \\
\text { impulses } \\
\text { divided by } \\
\text { channels }\end{array}$} & \multirow[t]{2}{*}{$\begin{array}{l}\text { Middle activity } \\
\mathbf{N}_{15}\end{array}$} & \multirow{2}{*}{$\begin{array}{c}\begin{array}{c}\text { Category } \\
\text { of rock burst }\end{array} \\
1\end{array}$} \\
\hline & & & & 1 & 2 & $\mathrm{~N}_{1}$ & $\mathrm{~N}_{2}$ & & \\
\hline 1 & $10: 53$ & 1 & 10 & 10 & 19 & 119 & 119 & 2,975 & HAZARD \\
\hline 2 & 11:07 & 1 & 10 & 15 & 20 & 95 & 95 & 2,375 & NOT HAZARD \\
\hline 3 & $11: 23$ & 1 & 5 & 15 & 20 & 21 & 21 & 1,05 & NOT HAZARD \\
\hline 4 & 11:30 & 1 & 1 & 15 & 20 & 6 & 6 & 1,5 & NOT HAZARD \\
\hline 5 & $11: 38$ & 2 & 10 & 15 & 20 & 47 & 47 & 1,175 & NOT HAZARD \\
\hline 6 & $11: 55$ & 3 & 10 & 15 & 20 & 209 & 209 & 5,225 & HAZARD \\
\hline 7 & $12: 07$ & 3 & 5 & 17 & 23 & 198 & 198 & 9,9 & HAZARD \\
\hline 8 & $12: 17$ & 4 & 5 & 10 & 19 & 235 & 235 & 11,75 & HAZARD \\
\hline 9 & $12: 24$ & 4 & 5 & 15 & 20 & 103 & 103 & 5,15 & HAZARD \\
\hline 10 & $12: 35$ & 5 & 5 & 15 & 20 & 45 & 45 & 2,25 & NOT HAZARD \\
\hline 11 & $12: 46$ & 6 & 5 & 10 & 19 & 9 & 9 & 0,45 & NOT HAZARD \\
\hline 12 & $12: 55$ & 7 & 5 & 10 & 19 & 9 & 9 & 0,45 & NOT HAZARD \\
\hline
\end{tabular}

The high acoustic activity in situ "the North - 8" on marks from-540 m on - $240 \mathrm{~m}$ (fig. 3) was recorded from December 1 to December 10, 2017 on the Nikolaevsk mine (JSC Dalpolimetall MMC) ASCRP. Measurements by the local device were performed in mine caving (northern branch, North-8 block, horizon of-375 m) from December 5 to December 7 , 2017 year. 


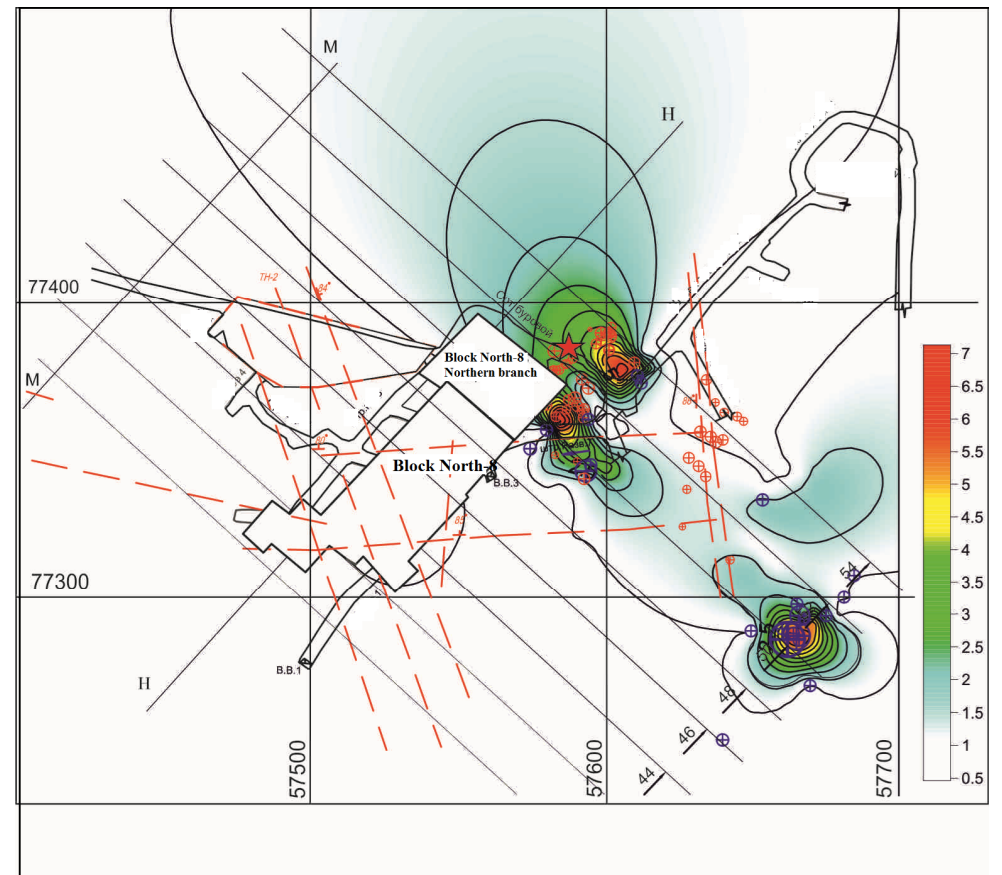

Fig. 3. The map of density of a spatial distribution of the centers of AE of the events recorded on the Nikolaevsk field by the automated Prognoz ADS control system from December 1 to December 10, 2017[3].

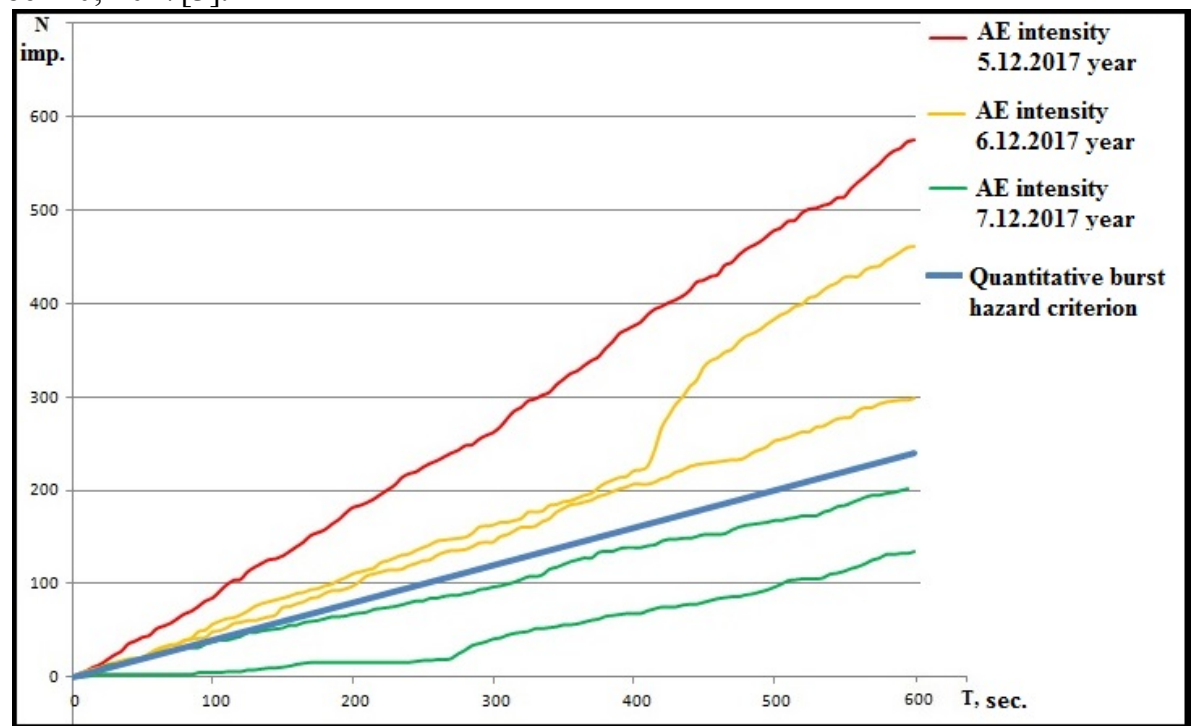

Fig. 4. The schedule of activity of impulses of AE (North-8 block horizon of-375 m, December 5-7, 2017).

Maximal intensity was identified by the device at $10 \mathrm{~h} 15 \mathrm{~min}$. (5.12.2017), fig. 4. The device indicated "HAZARD" [8, 9]. According the ASCRP indication and "Prognoz-L" data, the mine staff made the decision to close mine caving. After 2 days break the intensity of AE decreased and the device indicated "SAFETY", fig. 6 (9 h 50 min. 7.12.2017 measurement).

Mean values of main AE parameters (North-8 block, -375 m horizon):

- Frequency of impulses -10856 Hz; 
- Duration of impulses - $17 \mathrm{~ms}$;

- Amplitude of impulses - 28,0 dB

\section{Conclusions}

On the basis of use of the modern microprocessor and digital technologies. The geoacoustic portable device for local monitoring of burst hazard potential "Prognoz L" is developed and introduced. "Prognoz L" allows to record and determine the AE parameters in the conditions of technological noise.

Burst hazard research is carried successfully out by the local device in a complex with the automated control system of rock pressure (ASCRP). Research data are verified by numerical modeling of a spatial distribution of the centers of AE events.

The efficient algorithms and the software providing the registration AE signals are developed. They are applied for mine conditions. The following parameters of AE signals are determined: intensity of an acoustic emission; base frequency of impulses of $\mathrm{AE}$; duration, amplitude and the relative power characteristic of AE-events, etc.). The efficient algorithms and the software provide profound analysis of results of geomechanical monitoring.

The measurements of the generated impulses with the given parameters of frequency, amplitude and duration are performed. The results of measurements allow to estimate attenuation of a wave of signals for the distance up to 10 meters from the receiving converter of the device. These measurements were made for different types of rock deep horizons of the "Nikolaev" mine.

The representative volume of the experimental data for development of preliminary criteria of burst hazard of the deep horizons of the Nikolaevsk mine is collected.

\section{References}

1. Instructions for the safe conduct of mining operations in mines and non-ore deposits, facilities for the construction of underground structures, inclined and dangerous for mountain impacts (RD 06-329-99). GP NTC on safety in the industry of Gostehnadzor of Russia (2000).

2. G.I. Kulakov, G.E. Yakovitskaya FTPRPI. 2. (1993).

3. A.A. Tereshkin \& M.I. Rasskazov / Geomechanics and geodynamics of rock masses / European Rock Mechanics Symposium // Assessment of burst-hazard rock massif by geoacoustic method, P. 1627. 2. (2018).

4. I.Ju. Rasskazov, B.G. Saksin, M.I. Potapchuk \& P.A. Anikin./ Geomechanics and geodynamics of rock masses / European Rock Mechanics Symposium // The researches of bursthazard on mines in Russian Far East, P. 153. 1. (2018).

5. I. Y. Rasskazov, D. S. Migunov, P. A. Anikin, A. V. Gladyr, A. A. Tereshkin, D. O. Zhelnin. Journal of Mining Science. 51(3). P. 614-623. (2015).

6. A.S. Voznesensky Control systems for geomechanical processes. Publishing house MGGU, (2002).

7. Methodical instructions on seismoacoustic and electromagnetic methods for obtaining criteria for the degree of burst-hazard. VNIMI. (1986).

8. A.O. Rozanov, D.N. Petrov, A.M. Rozenbaum, A.A. Tereshkin \& M.D. Ilinov / Geomechanics and geodynamics of rock masses / European Rock Mechanics Symposium // Acoustic emission precursor criteria of rock damage, P. 669. 1. (2018).

9. I.Yu. Rasskazov, B.G. Saksin, V.A. Petrov, B.F. Shevchenko, V.I. Usikov, G.Z. Gil'manova. Izvestiya, Physics of the Solid Earth. 50 (3). PP. 444-452. (2014). 